\title{
TRAYECTORIAS DE VIDA DE PERSONAS TRANS EN EL ÁREA METROPOLITANA DE BUENOS AIRES (AMBA)
}

Gustavo Javier Rigueiral Susana Seidmann Universidad de Buenos Aires, Argentina

\section{RESUMEN}

Se presentan resultados de un estudio que aborda la construcción de los itinerarios de vida de personas trans en el Área Metropolitana de Buenos Aires (AMBA). El objetivo general del estudio consistió en indagar sobre los procesos de construcción de identidad y las trayectorias de vida de este colectivo. El objetivo específico se propuso identificar en las trayectorias de vida de las personas trans, puntos de conflicto, restricciones y facilitadores en el ejercicio de sus derechos. Se realizaron 16 relatos de vida a mujeres y varones trans. Se utilizaron como técnicas de recolección de datos, la entrevista en profundidad y la construcción de una línea de vida. Se realizó un análisis temático de los relatos y dibujos. Los resultados dan cuenta de los procesos de estigmatización y discriminación que han vivido y siguen padeciendo estas personas, así como también de las estrategias para afrontarlos.

\section{Palabras clave}

Personas trans - trayectorias de vida - vida cotidiana - estigmatización - construcción de identidad

\begin{abstract}
The results of a study that addresses the construction of trans life itineraries in the Metropolitan Area of Buenos Aires (AMBA) are presented. The general objective of the study consisted in investigating the processes of identity construction and the life trajectories of this group. The specific objective was to identify in the life trajectories of trans people, conflict points, restrictions and facilitators in the exercise of your rights. Sixteen life stories were made to transgender women and men. The in-depth interview and the construction of a lifeline were used as data collection techniques. A thematic analysis of the stories and drawings was carried out. The results show the processes of stigmatization and discrimination that these people have experienced and continue to suffer, as well as the strategies to face them.
\end{abstract}

\section{Keywords}

Trans people - life trajectories - daily life - stigmatization - identity construction 


\section{Ser trans en el Área Metropolitana de Buenos Aires}

La denominación "trans" se utiliza como un término genérico que incluye a todas las personas cuyo sentido de identidad de género difiere del género asignado al nacer e incluye a: travestis, transexuales y transgénero. En el ámbito anglosajón y de la producción académica de España, se suele utilizar transgénero como una categoría abarcativa de las diferentes identidades trans (Helien y Piotto, 2012; Vartabedian, 2014). Las personas trans han sido estigmatizadas y discriminadas y se las ha asociado a la delincuencia, al ejercicio de la prostitución, al consumo problemático de sustancias (Fernández, 2004) y a los trastornos mentales (Más Grau, 2010; Missé y Coll Planas, 2010).

Varios estudios realizados en AMBA, muestran que las transidentidades son uno de los grupos que vive en las peores condiciones de vida, con dificultades para el acceso a la educación, la salud, un trabajo formal y a la vivienda (AAVV, 2016; Berkins y Fernández, 2005; Bloch et al., 2010; INDEC, 2012; Ministerio Público de la Defensa, 2017; Rada Schultze, 2013).Investigaciones llevadas adelante en otros países de Latinoamérica, señalan similares condiciones de vulneración de derechos (Cabral y Hoffman, 2009; García Becerra, 2009). Según los estudios relevados, la expectativa de vida de una persona trans, en la región, es de 35 años. Esta situación está asociada a la expulsión temprana del hogar por parte de la familia de origen y en el caso de las feminidades trans a la incursión en la prostitución antes de cumplir los 18 años. Otros factores que inciden son: la administración clandestina de hormonas y siliconas, la exposición al contagio del VIH y los crímenes de odio (Berkins y Fernández, 2005; CIDH, 2015; Norton y Herek, 2012; Rada Schultze, 2013).

La lucha organizada de las asociaciones de personas trans logró que, en el año 2012, se sancionara en Argentina una ley de identidad de género (Ley 26.743). En dicha ley, se establece el derecho que tiene toda persona al reconocimiento de su identidad de género, al libre desarrollo de su persona y al acceso a la salud integral. La norma prevé que quienes así lo deseen puedan acceder a intervenciones quirúrgicas y/o tratamientos integrales hormonales para adecuar su cuerpo, incluida su genitalidad, a su identidad de género autopercibida, sin necesidad de requerir autorización judicial o administrativa.

En este contexto, se torna necesario generar conocimientos sobre la población trans, sus vivencias y sus problemáticas. De esta manera, se pretende contribuir a darle la voz a quienes por mucho tiempo se encontraron invisibilizadas/os para gran parte de la sociedad.

Con respecto al ámbito académico de la psicología, se observa un área de vacancia en el abordaje de la población trans, salvo los estudios que presentan un enfoque clínico - patologizante de estas expresiones de la diversidad sexo - genérica.

La investigación se propuso dar respuesta a los siguientes interrogantes: ¿Cómo inciden los procesos de estigmatización y discriminación en las trayectorias de vida de las personas trans en el AMBA? ¿Qué restricciones se les presentan por estigmatización o temor a la estigmatización?

Este estudio tuvo por objetivo general "Indagar sobre los procesos de construcción de identidad y las trayectorias de vida de personas trans del AMBA". En este artículo se aborda uno de los objetivos específicos, que consistió en "Identificar en las trayectorias de vida de las personas trans puntos de conflicto, restricciones y facilitadores en el ejercicio de sus derechos."

\section{La construcción de las identidades de género}

La identidad de género se constituye en una de las dimensiones de mayor importancia en la construcción de las identidades. El término remite a la adopción que las personas realizan de los géneros socialmente disponibles. Money y Ehrhardt (1972) la definen como "la monotonía, unidad y persistencia de la propia individualidad como masculina, femenina o ambivalente" (p.4) y es considerada una experiencia privada que se manifiesta a través del rol de género.

Diversos autores sostienen que desde la modernidad se ha instaurado una matriz de configuración de los géneros y los cuerpos. Se presupone a la heterosexualidad como el destino 
obligatorio de las personas confinando al ámbito de lo perverso y lo patológico a las otras orientaciones sexuales como las de gays, lesbianas y bisexuales y a las otras identidades de género como la de las personas trans (Butler, 2007; Foucault, 1976; Kosofsky Sedgwick, 1998). Butler (2007) define esta matriz como: “... la rejilla de inteligibilidad cultural a través de la cual se naturalizan cuerpos, géneros y deseos.” (p, 292). Las personas se vuelven inteligibles en la medida en que pueden ser categorizadas por los otros en un género que se ajuste a las normas reconocibles circundantes, "manteniendo coherencia y continuidad entre sexo, género, práctica sexual y deseo." (Butler, 2007, p. 72). De esta manera, se conforma un mundo con seres que merecen vivirlo y habitarlo y seres que son confinados a vivir vidas precarias en los límites de la humanidad.

\section{Método}

Se realizó un abordaje cualitativo con un diseño de tipo exploratorio.

\section{Participantes}

Se trató de una muestra de tipo teórica no probabilística. La misma quedó conformada por dieciséis participantes (doce mujeres y cuatro varones). La edad promedio de la muestra fue 37, 8 años. Se utilizaron como criterios de inclusión: que la propia persona se autodefiniera como travesti, transexual, transgénero, intersexual, femineidad trans o masculinidad trans, independientemente del sexo biológico al nacer; que fuera mayor de 18 años y residiera en el Área Metropolitana de Buenos Aires; que aceptara voluntariamente participar de la investigación firmando un consentimiento informado; que hubiera recurrido o no a tratamientos de readecuación quirúrgica u hormonal y por último, que no tuviera dificultad para comprender o expresar el idioma castellano.

Como procedimiento muestral se utilizó la técnica de la bola de nieve o red (Patton, 1990). Los primeros contactos se realizaron a través de las organizaciones de defensa de los derechos LGBTI, y luego, fueron las personas participantes las que hicieron referencia a otras para ser incluidas en la muestra, quienes a su vez refirieron a otras (Montero, 2006). El tamaño se determinó por el criterio de saturación conceptual o teórica, es decir, cuando al incluir nuevos participantes, la información obtenida no produce nuevos sentidos (Glaser y Strauss, 1967).

\section{Procedimiento}

El trabajo de campo se realizó entre diciembre de 2016 y enero de 2018. Se llevaron a cabo con cada participante, dos encuentros de aproximadamente 1 hora y 30 minutos cada uno. Se utilizaron las siguientes técnicas de recogida de información: 1. Relatos de vida (Bertaux, 1984; Kornblit, 2004; Mallimaci y Giménez Béliveau, 2006; Sautu, 1999). Esta técnica se encuentra dentro del enfoque biográfico junto con las historias de vida. Los relatos de vida están acotados al objeto de estudio del investigador y se centran en un aspecto particular de la experiencia de una persona. En el relato de vida, la persona es importante en su relato como ser individual y como representante de un contexto histórico y social expresando las problemáticas de un sector de la sociedad, como en este caso son las personas trans y las vicisitudes en sus trayectorias de vida. Por el contrario, las historias de vida suponen la reconstrucción biográfica realizada a partir de un estudio de caso sobre un actor social específico, utilizando diversos tipos de información y documentos, entre ellos, el propio relato de la persona. (Kornblit, 2004; Seid, 2013). Se utilizó una guía de preguntas diseñadas por los investigadores para indagar diferentes tópicas de las trayectorias de vida de estas personas. 2. La línea de vida (Gramling y Carr, 2004; Martin, 1997) es una técnica que permite indagar en los momentos más importantes de la trayectoria de vida de una persona desde su punto de vista, así como en los momentos de viraje o bisagra (Bertaux, 2005/1997, Kornblit, 2004). Se les solicitó a las personas participantes de la investigación (en adelante PPI), que mencionaran los momentos más importantes de su vida desde que habían nacido hasta el momento de la entrevista y que luego los graficaran de alguna manera y los valoraran negativa o positivamente. Se decidió recurrir a ambas técnicas, para poder realizar la triangulación de los datos obtenidos a partir de diferentes fuentes y así 
poder abordar la complejidad de los fenómenos (Minayo, 1997). Con respecto a las consideraciones éticas, se les presentó a las/os participantes un consentimiento informado que da cuenta del tema y objetivos de la investigación y se tomaron las medidas necesarias para conservar la confidencialidad y el anonimato de los datos recabados. A las/os participantes que así lo requirieron se les ofreció enviarles la desgrabación de las entrevistas.

\section{Análisis}

Se utilizó el análisis temático, que es un método para identificar, analizar y reportar patrones (temas) dentro de los datos (Braun y Clarke, 2006). Se realizó la desgrabación exhaustiva de las entrevistas realizadas a las/os participantes. Se buscaron las recurrencias y divergencias intra e interentrevista. Se recurrió a una estrategia inductiva de análisis de los datos, a partir de la construcción de las categorías emergentes. El análisis inductivo de los datos se realizó en dos fases, una textual, en la que se construyeron las categorías emergentes y otra conceptual, en la que éstas se relacionaron entre sí. La codificación inicial permitió identificar el contenido temático y los datos significativos, que dieron lugar a las interpretaciones y conclusiones posteriores. Se utilizó el programa informático Atlas. Ti 7.5

El análisis de los dibujos se organizó en dos etapas: en la primera, se diferenciaron los aspectos de estructura (descripción, organización, elementos graficados, emplazamiento, tamaño, detalles, sombreado, refuerzo o borrado). Esta primera sistematización de los datos, facilitó la identificación de aspectos comunes entre los dibujos y luego en la globalidad de los gráficos. Estos aspectos, junto con las verbalizaciones y aquellas partes que aparecieron con tratamiento diferencial, tanto por estar resaltado o por estar ausente, fueron tratados por medio del análisis de contenido (Bardin,1986). Los relatos de las entrevistas y las verbalizaciones al momento de realizar los dibujos, se incluyeron como complemento interpretativo de las imágenes, de manera de evitar que las interpretaciones se basaran en los preconceptos del investigador. En la segunda etapa se procedió a la categorización, a partir de la construcción de categorías emergentes de los datos, que permitieron caracterizar las trayectorias de vida de las/os participantes.

\section{Resultados}

Se identificaron, en las trayectorias de vida, procesos de dos tipos: los que les restringieron el acceso y ejercicio de los derechos y los que facilitaron el fortalecimiento de la identidad de estas personas y en consecuencia promovieron el poder constituirse en sujetos que puedan participar en la exigibilidad de sus derechos.

\section{Procesos que obstaculizan y restringen el ejercicio de los derechos}

En todos los relatos de vida las/os participantes dieron cuenta de las violencias de las que fueron blanco, desde la infancia por manifestar una expresión de género o una orientación sexual no acorde a lo esperable, desde una perspectiva heterosexista. Los escenarios más nombrados en los cuales las PPI han vivenciado este tipo de situaciones han sido la escuela, la familia de origen, el espacio público y el ámbito laboral.

La estigmatización y discriminación en el ámbito escolar. En los siguientes extractos de entrevistas las participantes refieren a varios hechos sucedidos en su paso por la escuela:

"En séptimo grado había dos maestras como que...que eran medias dictadoras, y yo me sentaba con una compañera y ino! era la fila de los varones y la fila de las mujeres. $Y$ yo me sentaba con mis compañeras y como era varón me separaban y yo me empacaba y no quería, no quería y me mandaban a dirección y toda esa rebeldía propia de la edad ¿No? Estee... y después siempre me acuerdo que una de las maestras cuando hacía...se hacía... en los últimos tres meses de escuela, de séptimo grado te preguntaban ¿qué vas a 
hacer cuando seas grande ¿No? Y a todos les preguntaba y a mí no. Entonces, yo le pregunté a la maestra:

-¿Y a mí no me va a preguntar qué quiero ser cuando sea grande?

Y me dice: -No. Porque ;las personas que nacen como vos no sirven para nada! Entonces yo le dije: - ilgual yo lo voy a decir!

$Y$ me paré y dije: -yo quiero ser actriz, voy a ser cantante y astronauta. Nada que ver una cosa con la otra (sonriendo). Mis compañeros se ré́an y la maestra no anotó nada en mi hoja de orientación vocacional, fue vacía. Ella no puso nunca todo lo que yo dije." (N, 46, mujer trans).

"Siempre cuento que mis recreos eran en dirección o en la sala de profesores, porque los chicos me escupían, pero nunca pensé en dejar la escuela. (L, 30 años, MT)

Este tipo de situaciones coinciden con los resultados de los estudios que describen que el primer escollo con el que se encuentran las personas trans luego del hogar, son las situaciones violentas en el escenario escolar. Estos hechos que se producen de manera sistemática, son uno de los factores que inciden muchas veces el abandono escolar (Cabral, 2012; Capicúa, 2014)

Cuando la discriminación comienza en casa. En varios de los relatos, las situaciones de discriminación y estigmatización en la infancia y en la juventud, se dieron en el contexto de la propia familia. En los siguientes extractos de entrevistas las PPI refieren este tipo de hechos:

"Mis hermanos decían como que yo tenía la culpa de que mi mamá se había enfermado. Eso nos decían a mí y a mi hermano. Tengo un hermano que es gay. Siempre nos recalcaban que mi madre se había enfermado por culpa de nosotros." (V, 33, mujer trans)

"Fue muy difícil, desde mi infancia ya me mandaban al psicólogo porque las maestras de jardín decían que tenía actitudes femeninas. Mi familia no lo aceptaba, mi papá me pegaba mucho. Me hacía hacer trabajo pesado del campo que suelen hacer los hombres, juntar troncos leñas, andar con las vacas, como a mis hermanos, pero lo intensificaba más en mí para modificarme." (L, 30 años, mujer trans)

A veces el rechazo por parte de los familiares supone la expulsión del hogar. Así le sucedió a I, de 29 años, una de las mujeres participantes quien relata lo siguiente:

"A mí me crió mi abuelo, mi mamá falleció cuando yo tenía meses, me crió mi abuelo hasta que cumplí catorce años, en ese año él fallece, me quedé en la lona, mis tíos me echaron de mi casa, y me quedé viviendo en la calle."

Este tipo de circunstancias de expulsión temprana de la familia es un patrón que se repite en muchas biografías de las personas trans y que ha sido señalado en diversas investigaciones (Álvarez Broz, 2017; Fernández, 2004; Meccia, et al, 2005; Sandoval Rebollo, 2008; Vidal - Ortíz, 2014).

Las trabas para el acceso y permanencia en el ámbito laboral. Las personas trans tuvieron y tienen muchas dificultades para acceder al mundo laboral (Pérez Álvarez, et al, 2013; Carvalho, 2006; Rada Shulze, 2016). Al analizar la situación en la que se encontraban las 16 PPI con respecto a esta área, antes de la aprobación de la LIG, se puede observar lo siguiente: 
- cuatro del total de las doce mujeres trans obtuvieron trabajos alternativos al comercio sexual ya habiendo transicionado (una en espectáculos, otra en una fábrica y dos como cuidadoras de personas);

- cinco de los participantes (cuatro mujeres y un varón) accedieron a sus puestos laborales en el pasado y fueron haciendo la transición conservando sus puestos, salvo una M.T. que fue despedida antes de transicionar, debido a un cambio de gestión en el gobierno de Ciudad Autónoma de Buenos Aires;

- Una mujer y un varón realizaron trabajos temporarios antes de transicionar, en el área de gastronomía como lavacopas y camareros.

Varias de las mujeres participantes narraron momentos en que fueron en la búsqueda de un puesto de trabajo y fueron rechazadas. Esta cuestión hizo que desistieran en la búsqueda de un trabajo formal e incursionaran o prosiguieran en el ejercicio de la prostitución. Tal como lo relatan en los siguientes pasajes:

"Estaba hace tres años trabajando de niñera en $C$ (su provincia natal), tenía ganas de venir a Buenos Aires, pensando que con un título iba a conseguir trabajo. A Buenos Aires que la pintan, como 'gay friendly', pensé voy a conseguir trabajo. $Y$ vine y la discriminación fue tremenda, más fuerte que en la provincia, no lo podía creer. Me cansé de buscar trabajo, ni siquiera de pedagoga, de limpieza, de moza, de lavacopas y no conseguía. Me estaba quedando sin plata y no quería volver a C. Caminando por Florida, Lavalle, dejando curriculums, veo una chica travesti que me dijo que no iba a conseguir trabajo y la único era ejercer la prostitución." (L, 30 años, M.T.)

“...una vez fui a buscar un trabajo siendo trans, hace mucho, cuando quería buscar por otro lado (se refiere como alternativa al ejercicio del comercio sexual), intenté...buena onda el muchacho que me atendió, yo estaba discreta, sino la gente te mira y te dice mirá el maricón o mirá la travesti (...) y este chico me dijo. 'No es por nada, todo bien. Si te pongo en el mostrador, tal vez podría llegar a tener problemas con los clientes que por ahi se zarpen o digan una boludez o alguna mujer que no le guste que la atiendan' y sutilmente me dejó afuera, me dolió un poquitito...en mi provincia siempre también pasó eso también.” (G, 38 años, M.T.)

Por otra parte, en el caso de las personas que lograron acceder a un puesto laboral, debieron enfrentar los prejuicios y las acciones discriminatorias por parte de algunos de sus compañeros de trabajo. Al respecto $\mathrm{V}$, una de las M.T., recuerda cuando trabajó en una fábrica de cinturones y carteras y había que hacer horas extras en diversos sectores para llegar a fin de mes y entonces afirma:

“...yo me iba a todos los sectores y saludaba a todos, pero había varones que no venían ¿Por qué? Porque estaba yo. Con las mujeres era excelente la relación, mates, charlas. Las mujeres por ahi sentís una discriminación pero a nivel competencia femenina...sana... a ver quién tiene las tetas más grandes...esas cosas de chicas. Pero los varones, el machismo es que no querían estar al lado mío, y la idea era: 'No, yo no voy a trabajar con este...' y ahí se viene la frase o 'Prefiero no hacer horas extras', cosas así."

Las dificultades en el acceso a la salud. Las biografías de las PPI se hallan atravesadas por situaciones de exclusión o el temor a ser excluidas en los distintos efectores de salud. Muchas de ellas recurrieron en el pasado a tratamientos clandestinos o de forma casera y al consumo de hormonas por recomendación de conocidos. Así lo refieren en los siguientes pasajes de entrevistas:

"Me hice la nariz, me hice los pómulos, la nariz, los ojos, la frente... hace mucho tiempo... En la frente por ejemplo te inyectan, es como un Botox ${ }^{\circledR}$ o acrílico... pero que dura más... Me operé el cuerpo, consumí muchas hormonas... En ese tiempo no se veía a 
un endocrinólogo... comencé por amigas tomando pastillas e inyectándome Perlutal $(e s$ un anticonceptivo inyectable), últimamente dejé un poco para no engordar. La silicona me la inyectaba por una chica que no era especialista, que nos hizo el cuerpo a muchas de nosotros, también es un riesgo... De salud estoy bien gracias a Dios. Algunas chicas sufrieron cosas feas, sobre todo en los noventas." ( $G, 38$ años, MT)

Otra de las participantes (V, de 37 años) relata las experiencias de sus amigas que recurrieron a las siliconas líquidas y su incorporación a partir de la utilización de jeringas de las que se usan para inyectarle la anestesia a los caballos.

“... yo tuve amigas que, iban a la farmacia y compraban el frasco de medio litro, un litro y las personas trans que eran las más veteranas te decían: 'Ahhh...no te hagás problema, yo te lo soluciono todo'

Entrevistador: Compraban el frasco ¿de qué?

$V$ : De silicona líquida. Inyecciones para anestesiar caballos eran las que se usaban para modelar el cuerpo. Se usaban una especie de correas, como armazones en los pechos y en la cola, y a través de esos armazones se inyectaba el líquido, que era intramuscular, que no te iba a pasar nada...etc. Vos salías, hecha una vedette y podías salir a trabajar."

En algunos casos, estas prácticas han tenido consecuencias negativas para la salud e incluso la muerte de muchas mujeres trans y travestis. L. de 30 años, relata las complicaciones que le trajo inyectarse silicona líquida en los glúteos:

"Una chica travesti, que es conocida en el ambiente por inyectar silicona, me la recomendaron y me inyectó. $Y$ ahora me trae problemas, me duele, es muy sensible el cuerpo, me toco, me rasco y por la gravedad se cae y no quiero que vaya a la pierna. Parece que el material invadió el hueso de la cadera, me hice una ecografía y tengo trocanteritis. El cuerpo ante la silicona produce una reacción, se inflama y eso molesta. Ahora saqué turno con un cirujano plástico para ver cuánto me sale."

\section{Procesos que contribuyeron al ejercicio de los derechos}

En las entrevistas y líneas de vida se identificaron varios acontecimientos y procesos que contribuyeron a que estas personas se sintieran fortalecidas y pudieran exigir vivir vidas vivibles. Entre ellos se destacan los siguientes:

Los refugios en la infancia y en la adolescencia en un contexto hostil. Algunas PPI mencionan en sus relatos a determinadas figuras entre los adultos, ya sea de sus familias o por fuera de ellas, que en la infancia o en la adolescencia aceptaron sus modos de ser y las dejaron actuar con libertad. De esta manera, los espacios compartidos se constituyeron en un lugar de cuidado y/o protección frente a los demás escenarios hostiles.

G, una M.T. de 38 años, cuando tenía 3 años, al separarse sus padres es dejada al cuidado de un matrimonio de personas mayores. Al llegar a cuarto grado de la escuela primaria, menciona que tuvo una maestra que le daba mucho cariño y por la cual se sentía muy apegada y afirma es sus palabras:

"Ella era tan buena, era tan amorosa (...) la casa de ella quedaba cerca de la escuela (...) me llevaba ahí, me ayudaba a hacer las tareas (...) me sentía cómoda ahí, me sentía querida (...) después yo ya de grande la iba a visitar a mi maestra buena onda." 
La participante relata que incluso repitió de grado a propósito para poder seguir estando con su maestra. Otra de las PPI, describe así la existencia de un espacio donde era aceptada sin miramientos ni violencias:

"En el barrio siempre me acuerdo que a dos casas de mi casa, había una modista (...) que se daba cuenta, yo me la pasaba ahí, no me decía nada, estaba todo bien, hasta con los hijos que jugábamos, era como una casa inclusiva. Siempre si me venían a buscar a casa, yo estaba ahí, en la casa de la modista. Porque era como un resguardo, me sentía segura, miraba la tele, me sentía cómoda." ( $V, 33$ años).

D. de 23 años, uno de los VT, señala como un hito importante en su vida, los momentos que pasó con su abuela cuando tenía entre 7 y 8 años y los evoca de la siguiente manera:

"Ella era una persona que me respetaba más allá de todo. Si yo me quería comportar de una manera ella me dejaba. Persona que según mi vieja era machona, que le gustaba usar pantalones de jogging, le gustaba bailar murga (...) siempre tuvo pelo corto, usaba remeras (...) Si yo quería usar eso, ‘Dejala que haga lo que quiera!', déjalo en todo caso. (...) Ella no me ponía limitaciones en nada, ella me dejaba ser. No me limitaba en los juegos, ni en la comida, ni en nada. Ella me dejaba ser libre..., yo quería estar siempre con ella..."

Las Salidas del armario. Todas las PPI destacan como un momento transcendental en sus itinerarios biográficos él o los instantes en que se dieron cuenta acerca de lo que les pasaba con su orientación sexual y/o su identidad de género y la posterior revelación a algunas de las personas importantes en sus vidas. Varias de ellas nominan ese momento utilizando la expresión "me cayó" o "les cayó la ficha". La primera utilización de este término, alude al propio darse cuenta de lo que les sucedía, ya sea, porque vieron a alguna persona trans en los medios masivos de comunicación, porque concurrieron a psicoterapia o porque entraron en contacto con otras personas trans cara a cara. Estos procesos subjetivos pueden inferirse de los siguientes extractos:

"Estaba en la computadora, y tengo un tío que es bastante facho, ya hacía un tiempo que me venía cayendo mal, yo estaba boludeando en Facebook y mi tío tirando bosta, veo que tiene una foto que decía 'pito y tetas para todos, ley de identidad de género'. Con una foto de fondo muy ridiculizante todo, pero más allá de eso, había chicas y había chicos a la vez, y ahi fue una locura, me fue cayendo todo." (J, 28 años, V.T.)

"A partir de los doce años se me cae la ficha, cuando lo genital empieza a jugar un rol importante, ahi es cuando entro en todos estos conflictos de ansiedad y depresión, sentía que había como una pelea, me costó instalarme como una identidad femenina hacia los demás porque yo tenía como una pelea interna más con mi propio cuerpo, por eso creo que no me molestó mi nombre exterior, como si no pudiera con todos los frentes y era mi lucha interna." (N, 42 años M.T.)

La segunda forma en que las PPI utilizan el término "caerles la ficha", remite a cuando ellas les revelaron a otros acerca de su identidad trans y esas personas pudieron captar en algún horizonte de inteligibilidad lo que venían percibiendo y tipificarlo en una categoría. Como lo expresa M de 37 años, una de las MT entrevistadas:

"Mirá la gente que me quiere me ve más contenta. A la gente que me quiere me ve contenta, la gente que me quiere le terminó de cerrar algo. Mucha gente utilizó la expresión: '¡Ah! Me cayó la ficha' o 'Me cerró' (se sonríe).” 


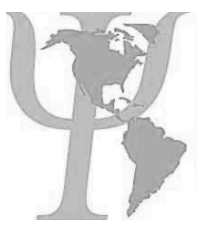

La salida del armario, lejos está de ser de un día para el otro. Tal como indica Blasi (2014), el closet o armario supone varias fases privadas donde la persona sufre miedo, vergüenza, desconcierto, confusión y no es fácil enfrentar un universo simbólico binario y heteropatriarcal. De esta manera, en algunos de los casos, las PPI primero abandonaron el closet pudiendo expresar su orientación sexual o recurrir a las identidades gay (en el caso de las M.T.) o lesbiana (en el caso de los V.T.) porque son más asequibles y aceptables en el horizonte de inteligibilidad de los cuerpos sexuados al que se refiere Butler $(2006 ; 2007)$. La segunda fase en la salida del closet hacia la identidad trans, se constituye al comenzar a realizar la transición con la adopción de la estética y los tratamientos hormonales o cirugías de acuerdo al género autopercibido.

En la figura número 1 que representa la trayectoria de vida de N, una M.T. de 42 años, se destacan dos etapas son su nombre femenino y un período de 13 años entre el 2000 y el 2013 donde vuelve a ser D. (su nombre asignado al nacer). En ese momento, según relata, se manifestaba con una identidad asexuada para poder estudiar y trabajar. N. recuerda que esta etapa no fue fácil y que abandonó su identidad femenina porque le causaba ansiedad "moverse" con el D.N.I. masculino y una apariencia femenina. Luego, vuelve a asumir su identidad femenina y decide operarse. La participante, identifica la cirugía de readecuación genital, como el punto bisagra en su vida (la escribe con color rojo) y la caracteriza como "...el momento más feliz incluida la etapa previa por la expectativa que había puesto en ella"

\section{Figura 1}

Linea de vida de $N, 42$ años, $M T$

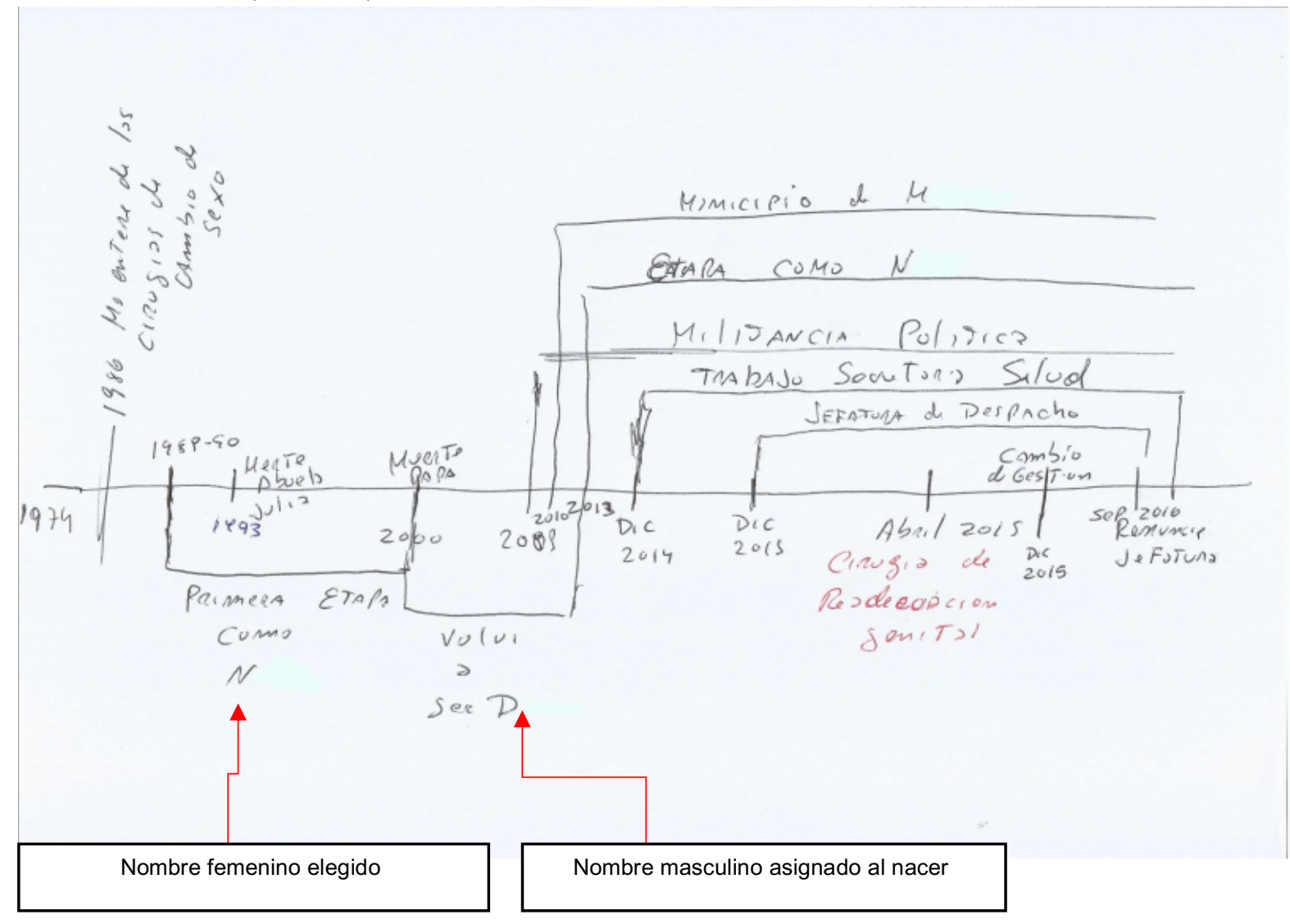

Una situación similar reseña G, otra de las M.T. participantes: 
"Como trans me asumí a los dieciocho... asumido totalmente, porque antes era como que gay, ni chicha ni limonada," afeminado, me inclinaba al género femenino...era más tranquila, no tan show “... Antes tuve mi etapa gay...Empecé a conocerme, a descubrir, los boliches gay, me enamoré por primera vez, todo en $S$. (su provincia de origen), fue lindo la verdad, lo recuerdo bien."

La metáfora de estar en el armario implica un lugar de secreto y opresión (Aristegui, 2012; Blasi, 2014; Vartavedian Cabral, 2012). Las PPI se representan ese período de sus vidas como "no tener libertad", creer que sus vidas no tenían sentido, ser un impostor o una impostora. Por otra parte relatan que manifestaban sentimientos de tristeza, ansiedad, depresión. Una de las entrevistadas, M. de 37 años, sintetiza muy bien este estado:

"yo sentía que viviendo la vida que estaba viviendo, era como estar todo el tiempo con un traje mal hecho"

Dos de las PPI relatan que intentaron suicidarse por el malestar que les generaba toda la situación y al sobrevivir transicionaron. Así lo manifiestan en los siguientes pasajes:

"A los 28, estaba en Estados Unidos. Tomé cianuro. Me salvaron de culo, pensé que me moría y ellos también pensaron eso. No me lo dijeron en ese momento. Después sí, me dijeron que no había ningún caso en el hospital que hayan podido salvar. Tuve mucha suerte. De ahí empecé con todo el tratamiento, pero ahí me empezaron a apoyar. Lo venía hablando con mi familia, pero no me apoyaban al cien por ciento, era muy complicado porque en Estados Unidos estaba ilegal. No tenía papeles, no podía hacer el cambio al cien por ciento." (U, 34 años, VT)

"Y como me quise matar y no funcionó transicioné. ¡No tenía plan B! ¡Es como que no tenía muebles! (Risas). Si la cuestión ahora siento que fue una estupidez, pero en ese momento fue la única salida. Al menos intentarlo" (M, 37 años, MT)

Por el contrario, la "salida del armario" remite a sensaciones placenteras y metáforas positivas, como "sacarse un peso de encima", "sentirse libre", "sentirse tranquilo" "ser claro", "encontrar la identidad" "ponerle palabras a lo que me sucedía". Esta situación les ha permitido salir fortalecidas, pudiéndose proyectar hacia el futuro como y en varios casos, generó que se ampliara su red de relaciones tal como lo afirma J, un VT de 28 años:

"Un día no aguanté más y así con todas esas preguntas que no tenían palabras, el último tiempo no salía de mi casa, estaba con pánico de ver gente, ahora no paro de ver gente... Me daba náuseas, no quería, me ponía nervioso, no podía interactuar con nadie"

La sanción de la LIG y su incidencia en los itinerarios biográficos de las personas trans. Todas las PPI dan cuenta de esta ley como un punto de viraje en sus vidas y la nombraron en sus relatos o la graficaron en las líneas de vida. La mayoría destaca haberse sentido de una manera positiva consigo misma/o, respaldada por una ley y fortalecida/o en su identidad. En los siguientes fragmentos se pueden pesquisar algunas de estas representaciones y sentimientos:

“...me siento como alguien más en el montón, no sé si totalmente integrada con la gente y todo... pero me siento más tranquila, saber que hay leyes.” (G, 38 años, MT)

"...poder ser yo, sin dar explicaciones (...) me dio estabilidad, seguridad, fuerza" (N, 46 años, MT) 
"Para mí fue un renacer, fue muy lindo." (L, 30 años, MT)

"El hecho de querer empezar a querer vivir, de poder sentir que vale la pena para algo." (U, 34 años, VT)

Por otra parte, se identifican cambios en las prácticas cotidianas. Varias PPI a partir de obtener el documento con su identidad autopercibida, decidieron inscribirse en alguna carrera terciaria y/o universitaria. Así lo expresa V, una MT de 38 años:

“Automáticamente, cuando a mí me dicen: 'Te llegó tu D.N.I', al otro día, fui al Instituto y me anoté para estudiar Magisterio. O sea, si mi decisión fue esa, en ese momento, imagináte cómo les habrá cambiado la vida a miles de chicas trans, para tomar decisiones en la vida, teniendo una identidad para golpear puertas."

La participación comunitaria. Varias de las PPI destacan como un momento importante en sus vidas el hecho de comenzar a militar en partidos políticos o en algunas de las organizaciones de defensa de los derechos de las personas trans como la Asociación Argentina de Travestis, Transexuales y Transgéneros (ATTTA). Estas/os participantes describen haber vivenciado transformaciones en las representaciones acerca de sí mismos y de los otros. Las mismas están asociadas a sentirse valorados, importantes, no egoístas, sentir que podían ayudar a otros para que no pasaran por lo que ellas y ellos pasaron. La psicología comunitaria conceptualiza estos procesos asociados al concepto de participación comunitaria. Ésta es considerada, no como un estado, sino como un proceso gradual en el cual se producen transformaciones tanto a nivel individual como colectivo. (Jiménez - Domínguez, 2008; Montero, 2004). Según Montero (2004) este proceso es: "organizado, libre, incluyente en el cual hay una variedad de actores, de actividades y de grados de compromiso, que está orientado por valores y objetivos compartidos, en cuya consecución se producen transformaciones comunitarias e individuales" (p. 109). Junto con la participación, se da el fenómeno del compromiso. Montero (2004) lo define como:

...la conciencia y el sentimiento de responsabilidad y obligación respecto del trabajo y los objetivos de un grupo, comunidad, proyecto o causa, que conduce a la persona a acompañar, actuar y responder ante ellos por las acciones llevadas a cabo. (p, 113)

Siguiendo a Montero (2004) la participación es condición para el fortalecimiento y la libertad de los sujetos y de las comunidades. La noción de fortalecimiento, según la psicóloga venezolana, remite a los procesos colectivos que les permiten a las personas poder adquirir herramientas personales y organizativas para tener un mayor control o dominio sobre sus vidas y los acontecimientos. De esta manera, permite incidir en los entornos y a su vez, transformarse a sí mismos. Los siguientes fragmentos evocados permiten dar cuenta de la importancia de estos procesos descriptos líneas arriba y de las transformaciones subjetivas que han operado en estas personas pudiendo pasar de sentirse estigmatizadas a personas que tienen el control de sus vidas y pueden resistir los embates de un orden social que en general las considera seres abyectos.

"ATTTA fue encontrar herramientas, pares, familia, el descubrirme a mí mismo en un millón de cosas, que puedo soñar, que yo puedo proyectarme, que puedo terminar mis estudios ¿qué quiero? ¿Qué puedo? ¿Qué no? eso me propuso la asociación (...) Yo hoy dando un taller y cuando empecé tenía 17 años y me daba miedo hasta decir mi nombre y toda la fortaleza y la formación me la dio ATTTA. (D, 23, VT) 
"Recibí el documento y a la semana empecé a trabajar en el municipio. Yo vi que había otras posibilidades. Que no tenía, que no tendría que ser la única yo, y ahí como que me posicioné yo en exigir lo que yo quería para mí y para todas las compañeras. Y fue un camino bastante de a poco, porque vos te das cuenta que la sociedad te excluyó toda la vida y nada... cuesta volver a insertarte en ese ambiente donde nunca te dejaron entrar. $(V, 33, M T) ”$

Estos resultados coinciden con la investigación de Aristegui, et al (2012) donde observan que las personas de la comunidad trans y gay al poder visibilizarse pueden apropiarse de ese recurso "para disminuir las situaciones de estigma y discriminación" (p, 86).

\section{Discusión y conclusiones}

El presente estudio se enfocó en indagar la incidencia de los procesos de estigmatización y discriminación en las trayectorias de un grupo de personas trans y las restricciones que les generaron para poder acceder a una vida digna de ser vivible tal como lo señala Butler (2017). Muchos de los resultados que se han presentado, dan cuenta de las múltiples violencias que han sufrido las PPI durante gran parte de sus vidas y las dificultades con las que se encontraron en sus itinerarios vitales. Estos hallazgos coinciden con las descripciones de otros estudios realizados con población trans (Coll - Planas, 2010; Fernández, 2004; Meccia et al, 2005; Missé y Coll-Planas, 2010; Vartavedian, 2012, 2014).

Por otra parte, se identificaron como facilitadores para el fortalecimiento identitario, a los procesos de salida del armario, el poder asumir la identidad de género, el apoyo por parte de algunas de las personas importantes de su red social, los cambios corporales (a pesar de poner en peligro la salud), la acción de las organizaciones LGBTI y los cambios en lo normativo.

La sanción de la LIG, es significada por las PPI como una bisagra, dado que les otorgó visibilidad a sus problemáticas y demandas ante el resto de la sociedad. Además, observaron cierta mejora desde su sanción en lo que respecta al acceso a la salud y en el fortalecimiento de sus identidades. Estos resultados coinciden con los hallazgos obtenidos por el estudio llevado adelante por Arístegui y Zalazar (2014).

Esta investigación tuvo como propósito devolverles a esas voces acalladas su protagonismo y contribuir al diseño de dispositivos de intervención desde las políticas públicas y las organizaciones de la sociedad civil con este colectivo de personas para que puedan dejar de ser ciudadanas/os de segunda. Otra de las contribuciones, consiste en aportar información que permita deconstruir y cuestionar los prejuicios existentes hacia el colectivo trans y así disminuir las distancias existentes hacia estas personas.

Se debería seguir profundizando en el estudio de las problemáticas de los varones trans y de las personas intersex que presentan diferencias con las de las mujeres trans y travestis y que recién están teniendo visibilidad tanto en lo académico como en la militancia.

Frente a la emergencia de discursos que tienden a ver una amenaza al orden patriarcal, heterosexual y binario, todas las acciones que tiendan a fortalecer y visibilizar a los colectivos oprimidos, permitirán contribuir a la construcción de un mundo más equitativo y más justo. 


\section{Referencias}

AAVV (2016). Situación de los derechos humanos de las travestis y trans en la Argentina. Evaluación sobre el cumplimiento de la Convención para la eliminación de todas las formas de discriminación contra las mujeres (CEDAW). Recuperado de http://tbinternet.ohchr.org/Treaties/CEDAW/Shared\%20Documents/ARG/INT_CEDAW_N GO_ARG_25486_S.pdf

Álvarez Broz, M. (2017) Familia “entre pares”. Relaciones de solidaridad y vínculos de fraternidad entre travestis y transexuales de la Argentina contemporánea. Revista Punto Género, (9), 131 - 152. ISSN 0719-0417

Arístegui, I. y Zalazar, V. (2014). Ley de Identidad de Género y acceso al cuidado de la salud de las personas trans en Argentina. Buenos Aires: Fundación Huésped. doi: 10.13140/RG.2.1.2278.7281 Recuperado de http://www.huesped.org.ar/wpcontent/uploads/2014/05/OSI-informe-FINAL.pdf

Arístegui, I., Vázquez, M., Dorigo, A. y Lucas, M. (2012). Percepciones y experiencias sobre estigma y discriminación en poblaciones trans, HSH y usuarios de drogas. Buenos Aires: Fundación Huésped con colaboración de Red de personas viviendo con VIH de Mar del Plata

Berkins, L. y Fernández, J. (coord.) (2005). La gesta del nombre propio. Informe sobre la situación de la comunidad travesti en Argentina. Buenos Aires: Ediciones Madre de Plaza de Mayo.

Bertaux (2005). Los relatos de vida. Barcelona: Bellaterra. (Edición original, 1997)

Bertaux, D. y Kohli, M. (1984). The life Story Approach: a Continental View. Annual Review of Sociology, 10, 215-235.

Bloch, C. et al. (2010). Condiciones de vulnerabilidad al VIH/sida e ITS y problemas de acceso a la atención de la salud en personas homosexuales, bisexuales y trans de la Argentina. Buenos Aires: Ministerio de Salud de la Nación.

Braun, V. y Clarke, V. (2006). Using thematic analysis in psychology. Qualitative Research in Psychology, 3, 77-101.

Butler, J. (2007). El género en disputa: El feminismo y la subversión de la identidad. Barcelona: Paidós. (Edición original, 1990)

Butler, J. (2017). Cuerpos aliados y lucha política. Hacia una teoría performativa de la asamblea. Buenos Aires: Paidós

Cabral, M. (2012). Algo ha pasado. En: Morán Faúndes, J., Sgró Ruata, M. y Vaggione, J. (Edits.). Sexualidades, desigualdades y derechos. Reflexiones en torno a los derechos sexuales y reproductivos. Córdoba: Ciencia, Derecho y Sociedad Editorial.

Capicüa (2014). Informe sobre Acoso Escolar en Argentina. La lógica de la discriminación a través de las voces de lxs estudiantes. Recuperado de www.capicuadiversidad.org

Coll Planas, G. (2010). La voluntad y el deseo. La construcción social del género y la sexualidad: el caso de lesbianas, gays y trans. Barcelona: Editorial Egales.

Comisión Interamericana de Derechos Humanos (2015). Violencia contra personas LGBTI en América. OEA

Congreso de la Nación Argentina. (23 de mayo de 2012). Ley de Identidad de Género [Ley 26.743]. Boletín Oficial de la República Argentina.

Fernández, J. (2004). Cuerpos desobedientes. Travestismo e identidad de género. Buenos Aires: Edhasa.

Foucault, M. (2005). Historia de la sexualidad. 1 - La voluntad del saber. Buenos Aires: Siglo XXI Editores. (Edición original, 1976)

Gramling, L. y Carr, R. (2004). Lifelines. A life history methodology. Nursing Research, 53, (3), 207 - 210. Doi: 10.1097/00006199-200405000-00008

Helien, A. y Piotto, A. (2012). Cuerpxs equivocadxs: hacia la comprensión de la diversidad sexual. Buenos Aires: Paidós 
INDEC (2012). Primera Encuesta sobre Población Trans 2012: Travestis, Transexuales, Transgéneros y Hombres Trans: Informe técnico de la Prueba Piloto Municipio de La Matanza 18 al 29 de junio 2012. Buenos Aires: Autor. Recuperado de http://www.indec.gov.ar/webencuestatrans/ pp_encuesta_trans_set2012.pdf

Jiménez - Domínguez, B. (2008). Ciudadanía, participación y vivencia comunitaria. En: Jiménez Domínguez, B. (Comp.) Subjetividad, participación e intervención comunitaria. Buenos Aires: Paidós

Kornblit, A. (coord.) (2004). Metodologías cualitativas en ciencias sociales: Modelos y procedimientos de análisis. Buenos Aires: Biblos.

Kosofsky Sedgwick, E. (1998). Epistemología del armario. Barcelona: Ediciones de la Tempestad. (Edición original, 1990)

Mallimaci, F y Giménez Béliveau, V. (2006). Historia de vida y métodos biográficos en: Vasilachis de Gialdino, I. (coord.) Estrategias de investigación cualitativa. Barcelona: Gedisa

Martin, E. (1997). The Simbolic Graphics life - line: Integrating the past and present through graphic imagery, art therapy. Journal of American art therapy Association, 14 (4), 261 - 267.

Mas Grau, J. (2010). Identidades gestionadas. Un estudio sobre la patologización y la medicalización de la transexualidad (tesis de maestría en Antropología y Etnografía) Universidad de Barcelona.

Meccia, E., Metlika, U. y Raffo, M. (2005). Trayectorias de vulnerabilidad de mujeres y travestis en situación de prostitución en el Sur del Gran Buenos Aires. En: Mallimacci, F. y Salvia, A. Los nuevos rostros de la marginalidad. Buenos Aires: Biblos.

Minayo, M. C. de S. (1997). El desafío del conocimiento. Buenos Aires: Lugar Editorial

Ministerio Público de la Defensa de la Ciudad Autónoma de Buenos Aires (2017). La Revolución de las Mariposas. A diez años de la Gesta del Nombre Propio. CABA: M.P.D. CABA

Missé, M. y Coll-Planas, G. (2010). La patologización de la transexualidad: reflexiones críticas y propuestas. Norte de salud mental, VIII, (38), 44-55. Recuperado de http://antigua.omeaen.org/norte/38/44-55\%20corr.pdf.

Montero, M. (2004). Introducción a la Psicología comunitaria. Desarrollo, conceptos y procesos. Buenos Aires: Paidós.

Montero, M. (2006). Hacer para Transformar. El método en la Psicología Comunitaria. Buenos Aires: Paidós.

Norton, A. y Herek, G. (2012). Heterosexuals' attitudes toward transgender people: Findings from a national probability sample of US adults. Sex roles, 68, (11-12), 738753.https://doi.org/10.1007/s11199-011-0110-6

Patton, M.Q. (1990). Qualitative Evaluation and Research Methods. (2nd Ed) Newbury Park: Sage Publications

Rada Schultze, F (2013). Curso de vida travesti. La imposibilidad de imaginarse un futuro como adultas mayores. X Jornadas de Sociología. Facultad de Ciencias Sociales, Universidad de Buenos Aires, Buenos Aires.

Sandoval Rebollo, E. (2008). Un lugar en el mundo. Condiciones de vida de Personas transexuales y transgénero en la Ciudad de México. Revista Trabajo social, (18), 112 - 125. Escuela nacional de Trabajo social.

Sautu, R. (comp.) (1999). El método biográfico. La reconstrucción de la sociedad a partir del testimonio de los actores. Buenos Aires: Editorial de Belgrano.

Vartabedian Cabral, J. (2012). Geografía Travesti. Cuerpos, sexualidad y migraciones de travestis brasileñas (Rio de Janeiro-Barcelona). Tesis de doctorado en Antropología Social y cultural. Universidad de Barcelona

Vartabedian, J. (2014). El alcance político de las trasvestilidades: acerca del potencial transgresor de las travestis. Annual Review of Critical Psychology, 11. Recuperado de http://www.discourseunit.com/arcp-11-gender-and-sexuality/ 
Vidal-Ortíz, S. (2014). Corporalidades Trans: algunas representaciones de placer y violencia en América Latina. Interdisciplina, 2, (3), 109-133.

Received: $12 / 11 / 2018$

Accepted: 09/07/2019

Una ficha es una pieza pequeña que se utiliza para poner en marcha ciertos aparatos. Cuando se utiliza en la alocución "caerle a uno o a alguien la ficha" significa entender completamente algo. (Conde, 2011)

"Esta expresión se usa en el sentido de no ser una cosa ni la otra.

" En la jerga trans es que una mujer trans esté vestida de manera exuberante, con tacos altos y muy maquillada para poder llamar la atención. 